\title{
MEGAEVENTOS E TURISMO: UM ESTUDO BIBLIOMÉTRICO DOS PERIÓDICOS BRASILEIROS DE TURISMO
}

MEGA-EVENTS AND TOURISM: A BIBLIOMETRIC STUDY OF BRAZILIAN TOURISM JOURNALS

\section{MEGA EVENTOS Y TURISMO: UN ESTUDIO BIBLIOMÉTRICO DE LOS PERIÓDICOS BRASILEÑOS DE TURISMO}

\author{
Amanda Cabral da Silva \\ Universidade de São Paulo - USP. \\ Mestranda em Turismo na Escola de Artes, Ciências e Humanidades da \\ Universidade de São Paulo - USP. \\ São Paulo, São Paulo, Brasil. \\ amanda.cabral012@gmail.com
}

\section{Debora Cordeiro Braga}

Universidade de São Paulo - USP.

Docente do Programa de pós-graduação em Turismo da Escola de Artes, Ciências e Humanidades da Universidade de São Paulo - USP. Doutora Ciências da Comunicação pela Escola de Comunicações e Artes da Universidade de São Paulo - USP.

São Paulo, São Paulo, Brasil. bragadc@usp.br

\section{Fillipe Soares Romano}

Universidade de São Paulo - USP

Mestrando em Turismo na Escola de Artes, Ciências e Humanidades da Universidade de São Paulo - USP. 
RESUMO: O presente trabalho, uma pesquisa descritiva exploratória, tem como principal objetivo a análise da produção do conhecimento científico dos periódicos nacionais brasileiros de turismo quanto a publicações acerca do tema megaeventos, entre os anos de 2010 e 2015, por meio de um estudo bibliométrico. Compreender o quanto os estudiosos estão disseminando os dados de suas pesquisas nesses canais de divulgação científica se faz importante pela atual conjuntura do Brasil como país sede de megaeventos. Dentre os 1.760 artigos publicados no período pesquisado, identificaram-se 12 artigos sobre megaeventos, dos quais nove abordavam megaeventos esportivos, um megaevento musical, outro sobre estratégia turística e um sobre turismo de megaeventos. Sendo assim, foi possível compreender a diversidade de estudos sobre megaeventos e como suas temáticas podem contribuir para o turismo.

PALAVRAS-CHAVE: megaeventos, turismo, bibliometria.

ABSTRACT: This is a descriptive, exploratory study that analyzes the production of scientific knowledge of Brazilian tourism journals in relation to the subject of "mega-events" in the period 2010-2015, through a bibliometric study. Understanding how scholars are producing and publishing knowledge about mega-events in Brazilian journals is important, in view of Brazil's leading role as a host country for sports mega-events in 2014 and 2016. Among the 1,760 articles published from January 2010 to December 2015, twelve articles on mega-events were identified. Of these, nine were about sports mega-events, one focused on a musical mega-event, another was about tourism strategy, and the last one was about mega-events tourism. Thus, it was possible to understand the diversity of studies on mega-events and how their themes can contribute to tourism.

KEYWORDS: mega-events, tourism, bibliometrics.

RESUMEN: Este estudio es una investigación descriptiva exploratoria que busca como principal objetivo el análisis de la producción del conocimiento científico de los periódicos nacionales brasileños de turismo en relación a las publicaciones acerca del tema de los mega eventos entre los años 2010 y 2015, mediante un estudio bibliométrico. Es importante comprender las producciones y publicaciones de los estudiosos acerca de mega eventos en los periódicos brasileños, ya que el país va a abrigar mega eventos deportivos en 2014 y 2016. De los 1.760 artículos publicados en el periodo de enero de 2010 a diciembre de 2015, se identificaron 12 artículos sobre mega eventos; de estos, nueve eran sobre mega eventos deportivos, uno sobre mega eventos musicales, uno sobre estrategia turística y uno sobre turismo de mega eventos. Así, fue posible comprender la diversidad de estudios sobre mega eventos y cómo sus temáticas pueden contribuir con el turismo.

PALABRAS CLAVE: Mega eventos; Turismo; Bibliometría. 


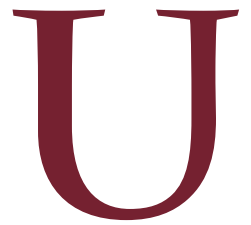

$m$ dos grandes desafios do estudo do turismo não está mais em investigar o fenômeno para torná-lo uma área consolidada na academia, mas sim em sair da tradicional produção de conhecimento em temas definidos como fundamentais ao turismo para dialogar com outras áreas do conhecimento, dado seu caráter transdisciplinar (Veal, 2011). Assim, este trabalho buscou explorar a aproximação entre o estudo do turismo e dos megaeventos, tema presente na atual realidade brasileira.

O estudo do turismo de eventos, como área de pesquisa, é recente. Foi especialmente nos anos 1980 que o tema ganhou maior relevância acadêmica. Nessas últimas quatro décadas, trabalhos sobre o tema se ampliaram, tornando-o área de pesquisa em diversas universidades ao redor do mundo (Getz, 2008). O progresso de uma base de estudo consolidada da área de turismo de eventos e, consequentemente, megaeventos, é primordial para o avanço do conhecimento científico-acadêmico, para contribuir direta e indiretamente com outras áreas do saber.

O presente trabalho analisa artigos sobre a temática megaeventos publicados nos últimos cinco anos, de janeiro de 2010 a dezembro de 2015, em periódicos nacionais de turismo com classificação Qualis da Comissão de Aperfeiçoamento de Pessoal de Nível Superior (CAPES). O objetivo é avaliar a importância e a relevância da temática frente a todos os artigos publicados no mesmo período. Investigar o que é publicado ajuda a compreender se há escassez ou concentração temática de autores nos estudos dos megaeventos pela vertente do turismo.

Esta pesquisa tem caráter descritivo e exploratório, sendo fundamentada em dados consolidados resultantes de uma análise bibliométrica, baseada na lei de dispersão do conhecimento científico de Bradford (Araújo, 2006), que busca compreender como se dá a publicação de trabalhos que relacionam turismo e megaeventos. $O$ estudo parte de um universo de 1.760 artigos publicados em 13 periódicos, dos quais apenas 12 trabalhos têm megaeventos no título ou nas palavras-chave. 
O artigo encontra-se estruturado do seguinte modo: a primeira seção é teórica, com a discussão de conceitos e relações entre turismo e megaeventos. Em seguida, é exposta a descrição do método e dos procedimentos metodológicos empregados na pesquisa. Depois é apresentada a seção analítica, que avalia dados quantitativos de artigos publicados nos periódicos selecionados; relaciona os anos de publicação dos 12 artigos específicos sobre megaeventos, com a realização dos megaeventos esportivos no Brasil; aborda dados sobre os autores e seus vínculos institucionais para verificar reincidências; e, por fim, discute dados qualitativos dos artigos analisados. As considerações finais ressaltam as respostas encontradas em razão do objetivo e suas relações com as referências teóricas adotadas, finalizando o trabalho.

\section{O TURISMO E OS MEGAEVENTOS: CONCEITOS E RELAÇÕES}

O turismo é um dos fenômenos mais marcantes do mundo contemporâneo. Essa colocação está embasada em literatura específica que afirma que esse é um fenômenocontemporâneo, apesardesuasorigensremotas, vistoqueodeslocamento é uma ação inerente ao ser humano. O homem, inicialmente compreendido como nômade, após a evolução social em vida urbana tornou-se sedentário, retomando a grande mobilidade apenas na atualidade (Ruschmann e Solha, 2006).

É fácil perceber que o turismo é um dos setores mais globalizados da economia mundial. Ele se desenvolveu e aperfeiçoou-se intensamente nos últimos 100 anos, sendo que o século XX chegou a ser chamado de século do turismo. Hoje estamos no Brasil, amanhã podemos estar, sem grandes complicações em Cingapura, na África do Sul ou na Holanda. (Panosso Netto, 2010, p.11, grifo do autor).

O fenômeno do turismo, altamente impactado pela globalização, transcende viagens que priorizam apenas o lazer como seu motivo principal. Cada vez mais, as viagens são planejadas e organizadas em prol de trabalho, estudos, eventos e diversos outros propósitos (Freitag, Tiscoski e Moretto Neto, 2010). Graças ao chamado processo de globalização, distâncias foram reduzidas, a comunicação progrediu e permitiu ao homem experimentar novas vivências nunca antes imaginadas (Silva, Carvalho e Silva, 2009). 
O Plano Nacional de Turismo 2013-2016, documento oficial brasileiro que consolida a política nacional de turismo, destaca o Brasil como destino internacional de eventos, com a $7^{a}$ colocação no ranking da International Congress and Convention Association (ICCA) 2011, com realização de 304 eventos (Brasil, 2013). Dados recentes da ICCA mostram que ocorreram 291 eventos internacionais no Brasil em 2014 (ICCA, 2014) - comparativamente aos 62 eventos realizados em 2003, houve aumento de 469\%. Não há dados sobre os fatores que motivaram a evolução, apenas o enaltecimento do setor de eventos. Acredita-se que a dinâmica do setor, a globalização, o período de estabilidade econômica do Brasil, na época, e a evidência mundial do país são fatores que contribuíram para esse salto.

Um evento é definido por Britto e Fontes (2002) como a junção de esforços e ações com planejamento prévio, no qual se busca o alcance de resultados estabelecidos junto ao seu público-alvo. Já o turismo de eventos tem como propósito o planejamento e a organização dessa demanda específica. De acordo com Getz (2008), o universo dos eventos é classificado com base em sua natureza, como o valor turístico atribuído. Assim, os eventos são divididos em dois grupos: eventos ordinários, que ocorrem sem um objetivo claro e específico; e eventos especiais, nos quais a duração é limitada, são atrativos para turistas, atraem a atenção da mídia e geram impacto nos locais em que são realizados. Os eventos especiais podem ser classificados de acordo com sua natureza, como celebrações culturais, eventos políticos e de Estado, eventos de arte e entretenimento, eventos de negócios e de comércio, eventos educacionais e científicos, competições esportivas e eventos privados. Getz (2008) também classifica os eventos especiais de acordo com seu potencial turístico, como os de principal interesse neste estudo, os megaeventos, os eventos marcantes e os eventos locais.

Para Lohmann e Panosso Netto (2008), os eventos são de especial interesse para o turismo. Tanto os que ocorrem uma vez, quanto os que se repetem com frequência, porque fazem parte da estratégia e da promoção marketing dos destinos.

Kotller, Gertner, ReineHaider(2006)discutememprofundidadeespecificidades e conceitos relacionados a marketing de destino, por eles chamado de marketing 
de lugar, porque a obra não se refere apenas a cidades turísticas. Defendem que marketing de lugares é o uso de ferramentas do marketing para enfrentar o desafio do crescimento no âmbito de lugares, atraindo investimentos, moradores e visitantes, e discutem como as comunidades e as regiões podem competir e desenvolver-se na economia global. Se os megaeventos evidenciam as cidades e os países sede na mídia, captam investimentos para esses espaços e exigem construções e adequações do espaço público, então são genuinamente uma ferramenta de marketing de lugar. Funk e Bruun (2007) reforçam que os eventos turísticos, como no caso dos megaeventos, são altamente promissores para o desenvolvimento da atividade turística, visto que tendem a ampliar e diversificar o mercado turístico no local sede.

Ao se discutir a influência dos megaeventos sobre os destinos, é relevante destacar que não são todos os eventos que podem ser definidos como 'mega', visto que existem muitas definições para o termo megaeventos. Apresentar a definição de Roche (1994), precursor dos estudos sobre megaeventos, é importante porque, apesar de ter sido construída no século passado, mantémse atual por abordar elementos como "duração", "resultados permanentes" - que podem ser entendidos como legados - e "local sede". Para Roche (1994), megaevento é "um acontecimento de curta duração, com resultados permanentes nas cidades e/ou países que o sediam e está associado à criação de infraestruturas e facilidades para o evento" (p. 19, tradução nossa). Entretanto, esse conceito não faz referências à comunidade local ou ao público visitante.

Já a definição de megaeventos de Hall (2006) perpassa pela grandiosidade de público, mas o que se destaca é o público-alvo definido, além de seus efeitos políticos, grande divulgação pela mídia, construção de diversas estruturas para servir a infraestruturas, como também o impacto econômico e social no país-sede.

Jago, Dwyer, Lipman, Lill e Vorster (2010) ressaltam a importância de planejamento para que os megaeventos estejam conectados a eventos menores que contribuam para uma imagem positiva do local-sede. A realização de um megaevento deve fazer parte de um plano de desenvolvimento. Essa questão é ainda mais evidenciada em países em desenvolvimento, nos quais os resultados tendem a propiciar maiores benefícios a longo prazo. 
Nessa linha de raciocínio, autores como Rodrigues, Dacosta, Pinto e Terra (2008), Reis (2008) e Santos (2000) destacam que os megaeventos são como grandes catalizadores e facilitadores de investimentos, no intuito de não ter um fim em si mesmo: quando estrategicamente planejados, propiciam efetivas transformações em níveis de infraestrutura, sociocultural, organizacional, como também impulsionam o setor de turismo, criam empregos, consumo, arrecadação de impostos, financiamentos.

As definições de megaeventos esportivos não se diferem significativamente das definições gerais de megaeventos, salvo destaque para o caráter competitivo e a realização periódica quadrienal, como a dos autores Ribeiro, Soares e Dacosta (2014), que adotam uma definição de megaeventos esportivos convergente com a definição de Roche (1994).

Para efeito de definição, compreendemos um megaevento esportivo como uma competição que, para ser realizada, necessita de grande aporte financeiro, logístico e humano. Apresenta também grande poder de atração de mídia e é realizada regularmente a cada período de 4 anos (Ribeiro, Soares e Dacosta, 2014, p. 450).

Assim, não se vê necessidade de diferenciar as características e as influências de megaeventos das de megaeventos esportivos nesta discussão teórica.

Quando se estudam megaeventos, as palavras legados e impactos são as primeiras a surgirem. Tavares (2007), com o intuito de diferenciá-las, coloca que os legados estão atrelados à ideia de longo prazo, com ações permanentes, que têm início no presente e que, se planejados adequadamente, podem ser positivos e benéficos, enquanto os impactos têm o caráter mais imediatista, com menor duração.

A reflexão de Pace, Hardt e Figueiredo (2015) sobre megaeventos congrega áreas que podem ser estudadas separadamente para a avaliação dos legados, inclusive os relacionados ao turismo:

O grande legado de megaeventos esportivos pode não estar ligado aos resultados dos jogos em si, mas a outros benefícios que chegam até à população. Grandes eventos são um importante catalisador para melhoria na qualidade de vida e podem acelerar o processo 
de reestruturação de uma cidade nas mais diversas áreas, como transporte, segurança, habitação e educação, entre outros. Nessa esfera, o turismo pode se transformar em um benefício que perdura não só durante o evento, mas também depois que ele termina. (Pace; Hardt e Figueiredo, 2015, p. 23, tradução nossa).

Mas vale apontar que os impactos podem não ser totalmente positivos ou totalmente negativos, inclusive o turístico. A escala e a dimensão dos impactos estão estritamente ligadas ao cenário analisado. Assim os legados dependem da área a ser analisada para serem considerados positivos, negativos ou um pouco dos dois (Owen, 2005).

Estudos mostram que há autores que diferenciam impactos de legados, reforçando que impactos são mais frequentemente considerados como consequência a um efeito adverso, um resultado prejudicial ou destrutivo. Enquanto o termo legado é mais frequentemente usado ao apresentar efeitos positivos. Portanto, é possível dizer que legado também tende a ser utilizado em associação com os efeitos que são de maior duração (Romano, Vico, Silva e Uvinha, 2015).

Assim, ao se estudar os pontos positivos, ou legado, dos megaeventos, a área de projeção da imagem do destino-sede aparece como um dos principais. Como uma possível alavanca para o turismo no Brasil, principalmente os esportivos, como no caso da Copa do Mundo Fifa realizada em 2014, e as Olimpíadas e Paralimpíadas de Verão Rio 2016. Além dos esportivos, todos os megaeventos sediados no país merecem grande atenção, pela oportunidade de o turista conhecer a localidade (cidades, país), estender sua estadia e, também, voltar em outras ocasiões (Marcellino, 2013). Em um mundo com distâncias reduzidas pelo advento dos avanços tecnológicos, políticos, econômicos, culturais, entre diversos outros, os megaeventos acabam por permitir uma espécie de vitrine da cidade e país que o sedia, por enfatizar seus aspectos positivos e torná-los conhecidos internacionalmente (Ishiy, 1998).

Desse modo, os megaeventos se colocam diante do mercado como uma grande ferramenta de marketing e, também, uma grande influenciadora de escolhas, perpassando diversas atividades socioeconômicas (Britto e Fontes, 
2002; Lohmann e Panosso Netto, 2008). Consequentemente, há grande contribuição na divulgação dos atrativos, recursos naturais, culturais e artificiais da sede do evento. Para o turismo, os megaeventos são uma oportunidade e um relevante negócio a ser desenvolvido (Alberini, 2014).

Também durante a realização dos megaeventos, o turismo é o setor mais disputado pelos países. Os produtos turísticos-como passagens aéreas, rodoviárias, diárias hoteleiras, refeições, suvenires e serviços em geral - são vendidos no atacado e consumidos em grande escala (Matias, 2008; Oliveira 2002).

Os megaeventos são equivalentes a outros esforços que cidades-sede adotam para o incremento do turismo e a visibilidade do destino, no intuito de aumentar o fluxo turístico internacional, impulsionando também o turismo doméstico. São estratégias que envolvem uma combinação de esforços urbanos e locais em prol do benefício não apenas da cidade, destino-sede, mas também do país. Os megaeventos têm a capacidade de reinventar a metrópole e alçála a um patamar de importância no contexto mundial. Bem-sucedidos, os megaeventos projetam a imagem da cidade em âmbito nacional e internacional (Tyler, Guerrier e Robertson, 2001).

Os diversos elementos ligados aos megaeventos são articulados diretamente com a proposta de desenvolvimento urbano e o segmento turístico, quanto à criação de infraestrutura e facilidades para sua realização, que podem e devem ser estendidas à comunidade local na busca por resultados benéficos para todos atores envolvidos. Com esse propósito, o megaevento é considerado bemsucedido quando propicia a divulgação de uma imagem positiva da cidadesede em âmbito internacional e permite legados positivos para a comunidade local e turistas, minimizando os impactos negativos.

\section{PROCEDIMENTOS METODOLÓGICOS}

O conteúdo de análise desta pesquisa é a produção científica sobre megaeventos nos artigos publicados em periódicos acadêmicos brasileiros de turismo no período de janeiro de 2010 a dezembro de 2015. A delimitação temporal foi escolhida em função da proximidade com a realização dos 
megaeventos esportivos no Brasil, embora Pace, Hardt e Figueiredo (2015) indiquem que pouco se publicou sobre o tema.

(. . .) apesar do fato do tema "megaeventos esportivos" estar repetidamente na mídia devido à escolha do Brasil como país-sede para a Copa do Mundo 2014 e a cidade do Rio de Janeiro como sede dos Jogos Olímpicos de 2016, os números não são significativos no campo científico com relação às contribuições acadêmicas sobre esse assunto. (Pace; Hardt e Figueiredo, 2015, p. 34, tradução nossa).

O processo de seleção das revistas iniciou-se com a busca na lista de classificação de periódicos Qualis-CAPES de 2014 usando-se como filtro de pesquisa a área de avaliação Administração, Ciências Contábeis e Turismo e o título Turismo. A lista geral relaciona 15 periódicos, dos quais dois são publicados na Argentina, portanto descartados de imediato. Apesar de a revista Arquiteturismo (Qualis B4) indicar em seu website que "é um periódico online mensal sobre as múltiplas relações entre arquitetura e turismo" (ARQUITETURISMO, s/d), os trabalhos que publicam apenas tangenciam turismo, dedicando-se mais a questões de patrimônio arquitetônico. Portanto, não se trata de um periódico especializado em turismo, de modo que também foi descartado da pesquisa.

Em seguida, realizou-se uma busca nos websites dos programas de pósgraduação em Turismo recomendados pela CAPES e detectou-se que há um periódico da área que não tem Turismo no título, mas é especializado e conta com classificação Qualis-CAPES. Portanto, no total, o universo de periódicos considerados nesta pesquisa somou 13 revistas.

Quadro 1 - Periódicos nacionais especializados de turismo selecionados para a pesquisa

\begin{tabular}{|c|c|c|c|}
\hline No. & ISSN & Título & $\begin{array}{c}\text { Classificação Qualis 2014 Área } \\
\text { de Administração, Ciências } \\
\text { Contábeis e Turismo }\end{array}$ \\
\hline 1 & $1677-6976$ & Caderno Virtual de Turismo (UFRJ) & B1 \\
\hline 2 & $1982-5838$ & Cultur: Revista de Cultura e Turismo & B4 \\
\hline 3 & $2316-5812$ & ReAT - Revista Eletrônica de Administração e Turismo & B3 \\
\hline 4 & $1980-6965$ & $\begin{array}{c}\text { Revista Acadêmica Observatório de Inovação } \\
\text { do Turismo }\end{array}$ & B4 \\
\hline 5 & $1983-9391$ & Revista Brasileira de Ecoturismo & B3 \\
\hline 6 & $1982-6125$ & Revista Brasileira de Pesquisa em Turismo & B2 \\
\hline 7 & $2236-6040$ & Revista Iberoamericana de Turismo & B4 \\
\hline
\end{tabular}




\begin{tabular}{|c|c|c|c|}
\hline No. & ISSN & Título & $\begin{array}{c}\text { Classificação Qualis 2014 Área } \\
\text { de Administração, Ciências } \\
\text { Contábeis e Turismo }\end{array}$ \\
\hline 8 & $1645-9261$ & Revista Turismo e Desenvolvimento (on-line) & $\mathrm{B} 4$ \\
\hline 9 & $1984-4867$ & Revista Turismo em Análise & $\mathrm{B} 2$ \\
\hline 10 & $2316-1493$ & Revista Turismo Estudos e Práticas & $\mathrm{B} 4$ \\
\hline 11 & $2178-9061$ & Rosa dos Ventos & $\mathrm{B} 3$ \\
\hline 12 & $1983-5442$ & Turismo e Sociedade & $\mathrm{B} 4$ \\
\hline 13 & $1983-7151$ & Turismo: Visão e Ação (online) & $\mathrm{B} 2$ \\
\hline
\end{tabular}

Fonte: Qualis-CAPES, 2014.

Como critério de seleção dos artigos, foram considerados os que tinham o termo "megaeventos" no título ou em palavras-chave. Artigos que não utilizaram a palavra "megaeventos" não foram considerados por não evidenciarem que o trabalho tratava diretamente o tema.

O método para realização deste estudo é a bibliometria que, segundo Veal (2011, p. 91), é "um termo acadêmico que se refere ao processo de identificar e estudar pesquisas anteriormente publicadas, relevantes ao tema de interesse". Araújo e Alvarenga (2011, p. 57) acrescentam que:

(. . .) a bibliometria não se relaciona ou se aplica somente à cienciometria, mas a outros contextos e insumos de conhecimentos passíveis de serem analisados por métricas diversificadas a partir de variáveis distintas e que aparecem na literatura publicada com denominações bem peculiares. (Araújo e Alvarenga, 2011, p.57).

A proposta é apresentar um quadro das revistas brasileiras de turismo quanto à sua produção acerca de megaeventos. Os dados foram coletados dos websites por meio de visitas aos endereços eletrônicos das revistas, procedimento compreendido como coleta de campo, visto que cada revista foi entendida como fonte primária de dados.

Apesar de o objetivo principal deste trabalho tratar de compreender como a temática megaeventos é abordada na comunicação científica especializada em turismo, este estudo bibliométrico permite análises mais amplas. Para Hall (2011), "a maior utilidade da bibliometria em estudos de turismo relaciona-se à avaliação de periódicos, bem como daqueles que neles publicam" (p. 17, tradução nossa). Assim, além de avaliar as temáticas dos artigos, as análises se estendem às revistas científicas e aos autores dos trabalhos selecionados para este estudo. 
A bibliometria pode adotar diversos métodos de análise e ser utilizada para uma enormidade de fins. O presente trabalho usa a Lei de Bradford, que também é conhecida como Lei de Dispersão do Conhecimento Científico (Araújo, 2006), para indicar a relevância dos periódicos pesquisados sobre o tema megaeventos. Segundo Donohue (1973, p. 17, apud Araújo, 2006, p. 15), essa lei se verifica ao colocar os periódicos em ordem decrescente de produtividade de artigos sobre determinado tema, podendo-se distinguir um núcleo de periódicos mais particularmente devotado ao tema e vários grupos ou zonas que incluem o mesmo número de artigos que o núcleo.

Como foi levantado um número pequeno de periódicos especializados em turismo e também um restrito número de artigos sobre megaeventos, não foi possível chegar ao "multiplicador de Bradford (Bm)", uma vez que não há um grupo de periódicos que se destaque como grupo principal de divulgação do conhecimento em turismo e megaeventos.

Estudos bibliométricos também podem verificar a aplicação da Lei de Lotka, que analisa a produtividade dos pesquisadores (Araújo, 2006). No início do século $\mathrm{XX}$, o estudioso que dá nome à lei descobriu que uma larga porção da literatura científica é produzida por um pequeno número de autores e, por outro lado, um grande número de pequenos autores se iguala, em produção, ao produzido por aqueles que publicam muito. Na presente pesquisa não foram destacados autores com produção suficiente que permitisse atestar a coerência da lei, já que nenhum autor aparece em mais de um artigo.

Em contrapartida, como a quantidade de artigos publicados sobre megaeventos nos periódicos especializados da área de turismo é pequena, optou-se por análises qualitativas que indicassem as especificidades dos artigos. Foram avaliados os tipos de pesquisas realizadas, as áreas objeto de estudo, os títulos, as palavras-chave e os resumos de cada artigo para compreender e avaliar os temas, a partir dos conceitos de megaeventos discutidos no referencial teórico. Com relação aos autores, listaram-se as instituições de vínculo na época da publicação do artigo e apontou-se a participação em grupos de pesquisa, programas de pós-graduação ou financiamentos, quando havia algum destaque a esse respeito, para verificar se existia concentração 
de pesquisas, apoio de alguma instituição de ensino superior ou agência de fomento ao tema megaeventos.

\section{MEGAEVENTOS NOS PERIÓDICOS NACIONAIS DE TURISMO}

Dentre os 1.760 artigos publicados no período de janeiro de 2010 a outubro de 2015, identificaram-se 12 artigos dedicados aos megaeventos nos periódicos de turismo com Qualis CAPES, conforme informação apresentada na Tabela 1.

Tabela 1 - Periódicos e quantidade de artigos publicados de 2010 a 2015

\begin{tabular}{c|c|c|c|c}
\hline Revistas & $\begin{array}{c}\text { Número de } \\
\text { edições }\end{array}$ & $\begin{array}{c}\text { Artigos } \\
\text { publicados }\end{array}$ & $\begin{array}{c}\text { Artigos sobre } \\
\text { megaeventos }\end{array}$ & $\begin{array}{c}\text { \% de artigos } \\
\text { sobre } \\
\text { megaeventos }\end{array}$ \\
\hline Turismo e Sociedade & 16 & 141 & 4 & 2,8 \\
\hline Revista Turismo em Análise & 18 & 180 & 1 & 1,1 \\
\hline Caderno Virtual de Turismo & 20 & 167 & 1 & 0,6 \\
\hline Cultur: Revista de Cultura e Turismo & 16 & 123 & 1 & 1,3 \\
\hline $\begin{array}{c}\text { Revista Acadêmica Observatório de } \\
\text { Inovação do Turismo }\end{array}$ & 15 & 77 & 1 & 1,8 \\
\hline Revista Turismo Estudos e Práticas & 10 & 57 & 1 & 0,6 \\
\hline Rosa dos Ventos & 21 & 178 & 1 & 0,7 \\
\hline Turismo: Visão e Ação & 18 & 150 & 0 & 0 \\
\hline $\begin{array}{c}\text { ReAT: Revista Eletrônica de } \\
\text { Administração e Turismo }\end{array}$ & 7 & 44 & 0 & 0 \\
\hline Revista Brasileira de Ecoturismo & 25 & 329 & 0 & 0 \\
\hline $\begin{array}{c}\text { Revista Brasileira de Pesquisa } \\
\text { em Turismo }\end{array}$ & 18 & 143 & 0 & 0 \\
\hline Revista Iberoamericana de Turismo & 13 & 109 & 0 & 0 \\
\hline Revista Turismo e Desenvolvimento & 9 & 62 & $\mathbf{1 2}$ & $\mathbf{0 , 7}$ \\
\hline Total & $\mathbf{2 0 6}$ & $\mathbf{1 7 6 0}$ & & \\
\hline
\end{tabular}

Fonte: Autores, 2016.

Como dito anteriormente, o número de periódicos especializados em turismo no Brasil é reduzido e ainda menor o número de publicações sobre megaeventos no período estudado. Assim, não há como analisar em profundidade a dispersão do conhecimento científico sobre megaeventos em turismo, mas é possível afirmar que $61 \%$ dos periódicos pesquisados publicaram artigos sobre a temática em questão e que há uma revista, a Turismo e Sociedade, que se destaca, com quatro artigos, em um número especial dedicado a megaeventos. Em segundo lugar, a Tabela 1 mostra que a Revista Turismo e Análise publicou dois artigos. Assim, esses dois periódicos formam um primeiro grupo com a concentração do

1 No editorial, o editor chama de Dossiê sobre Megaeventos (BAHL, 2014), no qual foram publicados oito artigos, mas apenas quatro usavam o termo megaeventos no título ou nas palavras-chave. 
conhecimento científico sobre megaeventos em turismo. As demais seis revistas, objeto deste estudo, publicaram apenas um artigo.

Outro dado analisado é a pouca representatividade que a temática megaeventos tem sobre o total de artigos publicados pelos periódicos no período de cinco anos pesquisados. A média é de $0,7 \%$ artigos sobre megaeventos. $\mathrm{Na}$ revista Turismo e Sociedade, esse percentual é de 2,8\%; e na Revista Turismo em Análise, $1,1 \%$. Os demais periódicos têm números muito diferentes de total de artigos publicados, mas dois deles (Revista Acadêmica Observatório de Inovação do Turismo e Revista Turismo Estudos e Práticas), embora com apenas um artigo publicado cada, terminam por ter um percentual de representação maior que o da Revista Turismo em Análise.

Resgatando os dados sobre a classificação Qualis da Tabela 1, não é possível identificar tendência de busca, por parte dos autores, por periódicos mais qualificados ou não, pois a Turismo e Sociedade é B4, a Revista Turismo em Análise é B2 e, entre os periódicos que publicaram um único artigo, há B1, B2, B3 e B4. Importante destacar que não existem periódicos especializados em turismo publicados no Brasil com Qualis superior a B1.

Quadro 2 - Ano de publicação por periódico

\begin{tabular}{|c|c|c|}
\hline Título & Revista & $\begin{array}{l}\text { Ano (volume, } \\
\text { número) }\end{array}$ \\
\hline 1. Megaeventos: uma estratégia de atração turística? & Revista Turismo e Sociedade & 2014 (v.7, n. 1) \\
\hline $\begin{array}{l}\text { 2. A gastronomia brasileira na Copa do Mundo de Futebol da } \\
\text { Fifa 2014: uma breve análise }\end{array}$ & Revista Turismo e Sociedade & 2014 (v. 7, n. 1) \\
\hline $\begin{array}{l}\text { 3. Megaeventos esportivos: reflexões sobre sustentabilidade e } \\
\text { suas relações com o turismo }\end{array}$ & Revista Turismo e Sociedade & 2014 (v. 7, n. 1) \\
\hline $\begin{array}{l}\text { 4. Copa do Mundo no Brasil: entre expectativas elevadas e } \\
\text { benefícios imprecisos }\end{array}$ & Revista Turismo e Sociedade & 2014 (v. 7, n. 1) \\
\hline $\begin{array}{l}\text { 5. Percepção do residente em relação a turismo de } \\
\text { megaevento: análise bibliométrica de periódicos } \\
\text { internacionais e latino-americanos }\end{array}$ & Revista Turismo em Análise & 2013 (v. 24, n. 3) \\
\hline $\begin{array}{l}\text { 6. Pesquisa de identificação do perfil e satisfação dos } \\
\text { turistas e visitantes de Brasília durante a Copa do } \\
\text { Mundo } 2014\end{array}$ & Revista Turismo em Análise & $\begin{array}{l}2015 \text { (v. 26, n. } 1 \\
\text { Especial) }\end{array}$ \\
\hline $\begin{array}{l}\text { 7. Megaeventos esportivos e relações internacionais como } \\
\text { estratégia de atração turística }\end{array}$ & $\begin{array}{c}\text { Revista Acadêmica } \\
\text { Observatório de Inovação do } \\
\text { Turismo }\end{array}$ & 2012 (v. 7, n. 1) \\
\hline $\begin{array}{l}\text { 8. A hospitalidade urbana de Fortaleza-CE frente ao } \\
\text { megaevento Copa do Mundo } 2014\end{array}$ & Turismo: Estudos e Práticas & 2013 (v. 2, n. 2) \\
\hline $\begin{array}{l}\text { 9. Cidade mercadoria cidade-vitrine, cidade turística: a } \\
\text { espetacularização do urbano nos megaeventos esportivos }\end{array}$ & Caderno Virtual de Turismo & $\begin{array}{l}2014 \text { (v. 14, n. } \\
\quad \text { Especial) }\end{array}$ \\
\hline
\end{tabular}




\begin{tabular}{|c|c|c|}
\hline $\begin{array}{c}\text { 10. Public participation in environmental impact } \\
\text { assessment (EIA) and major sports events: a } \\
\text { comparative analysis of the London 2012 Olympic } \\
\text { Games and the Rio 2007 Pan American Games }\end{array}$ & Rosa dos Ventos & 2014 (v. 6, n. 4) \\
\hline 11. Um modelo conceitual de megaeventos musicais & $\begin{array}{c}\text { Cultur: Revista de Cultura e } \\
\text { Turismo }\end{array}$ & 2015 (v. 9, n. 2) \\
\hline $\begin{array}{c}\text { 12. As mudanças na imagem das cidades de Curitiba e } \\
\text { Florianópolis: um estudo sobre os reflexos da divulgação das } \\
\text { cidades sedes para a Copa do Mundo da Fifa 2014 }\end{array}$ & Turismo Visão e Ação & 2015 (v. 17, n. 2) \\
\hline
\end{tabular}

Fonte: Autores, 2016.

O Quadro 2 relaciona os 12 artigos, com seus respectivos anos de publicação, a fim de compreender se o tema de megaeventos sediados pelo Brasil seria objeto de estudo dessas publicações. Como dito anteriormente, todos os artigos da Turismo e Sociedade foram editados conjuntamente em um número especial sobre megaeventos lançado no início do ano de 2014. Pelos títulos, pode-se afirmar que dois desses artigos são de temáticas ligadas à Copa do Mundo, que seria realizada em meados de 2014. Os outros dois tratam de temas correlatos à discussão de megaeventos e turismo, um discute o megaevento como estratégia de divulgação turística e outro aborda relações entre megaeventos, sustentabilidade e turismo.

Na Revista Turismo em Análise, há um artigo publicado em 2013 que, coincidentemente, traz um estudo bibliométrico, e outro em 2015 dedicado ao estudo da satisfação dos visitantes da Copa do Mundo de 2014 no Brasil, publicado em um número especial sobre o tema demanda turística.

Analisando os artigos publicados pelo segundo grupo de periódicos, há um publicado em 2012 que não trata dos megaeventos esportivos que seriam realizados no Brasil, mas de megaeventos como estratégia de marketing turístico internacional. Outro foi publicado em 2013 e o tema Copa do Mundo 2014 (Brasil) figura no título. Dois artigos foram publicados no ano de 2014 : um fez parte de um número especial sobre hospitalidade e políticas públicas de turismo e discutiu a questão da espetacularização de cidades em razão dos megaeventos esportivos; outro faz comparações sobre processo de avaliação de impactos ambientais entre as Olimpíadas de Londres 2012 e os Jogos PanAmericanos Rio 2007. Dos artigos publicados em 2015, um trata de megaeventos musicais e outro aborda diretamente os resultados da Copa do Mundo de 2014 na imagem da cidade de Curitiba. 
Assim, pode-se dizer que, dos artigos pesquisados, menos da metade teve como foco de estudo os megaeventos esportivos realizados ou em fase de organização à época das publicações.

O levantamento mostrou que, entre 2010 e 2012, é nula a publicação sobre a temática megaeventos em periódicos brasileiros e que, de fato, as realizações dos megaeventos esportivos no Brasil geraram pesquisas e, consequentemente, publicações, pois a Copa do Mundo de 2014 aparece em 5 dos títulos dos 12 artigos publicados, ou seja, $41 \%$.

O Quadro 3 detalha os autores, as instituições de vínculo e os programas de pós-graduação vinculados a cada artigo encontrado.

Quadro 3 - Dados sobre artigos, autores e vínculos institucionais

\begin{tabular}{|c|c|c|c|}
\hline Título & Autores & Instituição de vínculo & $\begin{array}{l}\text { Programa de pós- } \\
\text { graduação }\end{array}$ \\
\hline $\begin{array}{l}\text { 1. Megaeventos: uma estratégia } \\
\text { de atração turística? }\end{array}$ & Bruno Alberini & $\begin{array}{l}\text { Centro Universitário FAE } \\
\text { Business School, Paraná, } \\
\text { Brasil }\end{array}$ & $\begin{array}{l}\text { Especialização em } \\
\text { Marketing FAE }\end{array}$ \\
\hline $\begin{array}{l}\text { 2. A gastronomia brasileira na } \\
\text { Copa do Mundo de Futebol da } \\
\text { Fifa 2014: uma breve análise }\end{array}$ & $\begin{array}{l}\text { Maria Henriqueta S. } \\
\text { G. Gimenes-Minasse }\end{array}$ & $\begin{array}{l}\text { Universidade Federal do } \\
\text { Paraná, Brasil }\end{array}$ & $\begin{array}{l}\text { Doutorado em } \\
\text { História UFPR }\end{array}$ \\
\hline \multirow{2}{*}{$\begin{array}{l}\text { 3. Megaeventos esportivos: } \\
\text { reflexões sobre sustentabilidade } \\
\text { e suas relações com o turismo }\end{array}$} & Tassiana Hille Pace & $\begin{array}{l}\text { Pontifícia Universidade } \\
\text { Católica do Paraná, Brasil }\end{array}$ & $\begin{array}{c}\text { Doutorado em } \\
\text { Arquitetura e } \\
\text { Urbanismo na } \\
\text { PUCPR } \\
\end{array}$ \\
\hline & $\begin{array}{l}\text { Letícia Antunes } \\
\text { Hardt }\end{array}$ & $\begin{array}{l}\text { Pontifícia Universidade } \\
\text { Católica do Paraná, Brasil }\end{array}$ & $\begin{array}{l}\text { Programa de Pós } \\
\text { Graduação em } \\
\text { Gestão Urbana } \\
\text { PUCPR } \\
\end{array}$ \\
\hline \multirow{3}{*}{$\begin{array}{l}\text { 4. Copa do Mundo no Brasil: } \\
\text { entre expectativas elevadas e } \\
\text { benefícios imprecisos }\end{array}$} & $\begin{array}{l}\text { Olga Lúcia C. de F. } \\
\text { Firkowski }\end{array}$ & $\begin{array}{l}\text { Universidade Federal do } \\
\text { Paraná, Brasil }\end{array}$ & $\begin{array}{l}\text { Mestrado em } \\
\text { Geografia UFPR }\end{array}$ \\
\hline & Patricia Baliski & $\begin{array}{l}\text { Universidade Federal do } \\
\text { Paraná, Brasil }\end{array}$ & $\begin{array}{l}\text { Mestrado em } \\
\text { Geografia UFPR }\end{array}$ \\
\hline & $\begin{array}{c}\text { Alexandre Gomes } \\
\text { Ferreira }\end{array}$ & $\begin{array}{l}\text { Universidade Federal do } \\
\text { Paraná, Brasil }\end{array}$ & $\begin{array}{l}\text { Mestrado em } \\
\text { Geografia UFPR }\end{array}$ \\
\hline \multirow{3}{*}{$\begin{array}{l}\text { 5. Percepção do residente } \\
\text { em relação a turismo } \\
\text { de megaevento: análise } \\
\text { bibliométrica de periódicos } \\
\text { internacionais e latino- } \\
\text { americanos }\end{array}$} & $\begin{array}{l}\text { Marcelo Chiarelli } \\
\text { Milito }\end{array}$ & $\begin{array}{c}\text { Universidade Federal do } \\
\text { Rio Grande do Norte, } \\
\text { Brasil }\end{array}$ & $\begin{array}{l}\text { Mestrado em } \\
\text { Turismo UFRN }\end{array}$ \\
\hline & Sérgio Marques & $\begin{array}{c}\text { Universidade Federal do } \\
\text { Rio Grande do Norte, } \\
\text { Brasil }\end{array}$ & $\begin{array}{l}\text { Programa de Pós- } \\
\text { Graduação em } \\
\text { Turismo UFRN }\end{array}$ \\
\hline & Mauro Lemuel & $\begin{array}{c}\text { Universidade Federal do } \\
\text { Rio Grande do Norte, } \\
\text { Brasil } \\
\end{array}$ & $\begin{array}{l}\text { Programa de Pós- } \\
\text { Graduação em } \\
\text { Turismo UFRN } \\
\end{array}$ \\
\hline
\end{tabular}




\begin{tabular}{|c|c|c|c|}
\hline Título & Autores & Instituição de vínculo & $\begin{array}{l}\text { Programa de pós- } \\
\text { graduação }\end{array}$ \\
\hline \multirow{3}{*}{$\begin{array}{l}\text { 6. Pesquisa de identificação do } \\
\text { perfil e satisfação dos turistas e } \\
\text { visitantes de Brasília durante a } \\
\text { Copa do Mundo } 2014\end{array}$} & $\begin{array}{l}\text { Karen Graziele } \\
\text { Furlan Basso }\end{array}$ & $\begin{array}{l}\text { Universidade } \\
\text { Tecnológica de Dalian, } \\
\text { China }\end{array}$ & $\begin{array}{l}\text { Doutorado em } \\
\text { Gestão do Turismo } \\
\text { na Faculdade de } \\
\text { Economia e Gestão }\end{array}$ \\
\hline & $\begin{array}{c}\text { Thamyris Carvalho } \\
\text { Andrade }\end{array}$ & $\begin{array}{c}\text { Universidade de Brasília, } \\
\text { Brasil }\end{array}$ & $\begin{array}{l}\text { Mestrado em } \\
\text { Turismo no Centro } \\
\text { de Excelência em } \\
\text { Turismo da UNB }\end{array}$ \\
\hline & $\begin{array}{l}\text { Ariadne Pedra } \\
\text { Bittencourt }\end{array}$ & $\begin{array}{c}\text { Universidade Latino- } \\
\text { Americana e do Caribe, } \\
\text { México }\end{array}$ & $\begin{array}{c}\text { Mestrado em Gestão } \\
\text { do Turismo e Meio } \\
\text { Ambiente }\end{array}$ \\
\hline $\begin{array}{l}\text { 7. Cidade mercadoria cidade- } \\
\text { vitrine, cidade turística: a } \\
\text { espetacularização do urbano } \\
\text { nos megaeventos esportivos }\end{array}$ & $\begin{array}{c}\text { Gilmar Mascarenhas } \\
\text { de Jesus }\end{array}$ & $\begin{array}{l}\text { Universidade do Estado } \\
\text { do Rio de Janeiro, Brasil. }\end{array}$ & $\begin{array}{l}\text { Programa de Pós- } \\
\text { graduação em } \\
\text { Geografia UERJ }\end{array}$ \\
\hline \multirow{2}{*}{$\begin{array}{l}\text { 8. Um modelo conceitual de } \\
\text { megaeventos musicais }\end{array}$} & $\begin{array}{l}\text { Fabrício Silva } \\
\text { Barbosa }\end{array}$ & $\begin{array}{l}\text { Universidade Federal } \\
\text { do Estado do Rio de } \\
\text { Janeiro, Brasil }\end{array}$ & $\begin{array}{l}\text { Doutorado da Escola } \\
\text { de Engenharia de } \\
\text { Produção UNIRIO }\end{array}$ \\
\hline & $\begin{array}{l}\text { Annibal José } \\
\text { Scarvada }\end{array}$ & $\begin{array}{l}\text { Universidade Federal } \\
\text { do Estado do Rio de } \\
\text { Janeiro, Brasil }\end{array}$ & $\begin{array}{l}\text { Doutorado da Escola } \\
\text { de Engenharia de } \\
\text { Produção UNIRIO }\end{array}$ \\
\hline $\begin{array}{l}\text { 9. Megaeventos esportivos e } \\
\text { relações internacionais como } \\
\text { estratégia de atração turística }\end{array}$ & $\begin{array}{c}\text { Iata Oliver } \\
\text { Fernandes Silva }\end{array}$ & $\begin{array}{l}\text { Universidade Anhembi } \\
\text { Morumbi, Brasil }\end{array}$ & $\begin{array}{c}\text { Mestrado } \\
\text { em Hospitalidade } \\
\text { UAM }\end{array}$ \\
\hline \multirow{2}{*}{$\begin{array}{l}\text { 10. A hospitalidade urbana } \\
\text { de Fortaleza-CE frente ao } \\
\text { megaevento Copa do Mundo } \\
2014\end{array}$} & $\begin{array}{l}\text { Maraísa Nunes } \\
\text { Cavalcanti }\end{array}$ & $\begin{array}{c}\text { Faculdade Nordeste, } \\
\text { Brasil }\end{array}$ & $\begin{array}{c}\text { Bacharelado em } \\
\text { Turismo }\end{array}$ \\
\hline & $\begin{array}{l}\text { Ingrid Carneiro de } \\
\text { Lima }\end{array}$ & $\begin{array}{l}\text { Universidade Federal do } \\
\text { Ceará, Brasil }\end{array}$ & $\begin{array}{l}\text { Mestrado em } \\
\text { Geografia UFC }\end{array}$ \\
\hline \multirow{2}{*}{$\begin{array}{c}\text { 11. Public participation } \\
\text { in environmental impact } \\
\text { assessment (EIA) and major } \\
\text { sports events: a comparative } \\
\text { analysis of the London } 2012 \\
\text { Olympic Games and the Rio } \\
\text { 2007 Pan American Games }\end{array}$} & Gisele Silva Pereira & $\begin{array}{l}\text { Universidade Federal de } \\
\text { Pelotas, Brasil }\end{array}$ & $\begin{array}{l}\text { Departamento de } \\
\text { Turismo }\end{array}$ \\
\hline & $\begin{array}{l}\text { Suzana Maria de } \\
\text { Conto }\end{array}$ & $\begin{array}{l}\text { Universidade Caxias do } \\
\text { Sul, Brasil }\end{array}$ & $\begin{array}{l}\text { Programas de } \\
\text { Pós-Graduação em } \\
\text { Turismo da UCS }\end{array}$ \\
\hline \multirow{3}{*}{$\begin{array}{l}\text { 12. As mudanças na imagem } \\
\text { das cidades de Curitiba e } \\
\text { Florianópolis: um estudo sobre } \\
\text { os reflexos da divulgação das } \\
\text { cidades sedes para a Copa do } \\
\text { Mundo da Fifa } 2014\end{array}$} & $\begin{array}{c}\text { Stefanie Fontanete } \\
\text { Trotta }\end{array}$ & Não informado & $\begin{array}{c}\text { Graduação } \\
\text { em Relações } \\
\text { Internacionais }\end{array}$ \\
\hline & Vivian Iara Strehlau & $\begin{array}{l}\text { Fundação Getúlio } \\
\text { Vargas, São Paulo, Brasil }\end{array}$ & $\begin{array}{l}\text { Doutorado em } \\
\text { Administração de } \\
\text { Empresas }\end{array}$ \\
\hline & $\begin{array}{l}\text { Frederico de Araujo } \\
\text { Turolla }\end{array}$ & $\begin{array}{l}\text { Fundação Getúlio } \\
\text { Vargas, São Paulo, Brasil }\end{array}$ & $\begin{array}{l}\text { Doutorado em } \\
\text { Economia de } \\
\text { Empresas }\end{array}$ \\
\hline
\end{tabular}

Fonte: Autores, 2016.

O Quadro 3 revela que, no total, foram 24 pesquisadores que publicaram sobre megaeventos. Há quatro artigos com um único autor, quatro com dois 
autores e outros quatro com três autores. Vale destacar que nenhum autor se repete entre os artigos estudados.

Assim, é possível supor que os trabalhos publicados não geraram materiais suficientes para mais de um artigo ou que os estudos não são resultantes de grupos de pesquisa que investigam a temática com continuidade e intensidade para produzir artigos com constância. Tal desconfiança se baseia em resultados de outros estudos bibliométricos, como o realizado por Milito, Marques e Alexandre (2013), que esclarecem:

Nas revistas internacionais se observou 10 pesquisadores, no universo de 166, que publicaram mais de um artigo sobre o tema na última década (. . .) O fato de que existem autores que fazem 5 publicações ou mais em uma década, nas duas revistas internacionais mais relevantes da área e sobre o tema em questão, pode ser considerado um indicativo que existem especialistas internacionais sobre o tema. (p. 497).

Os dados referentes aos vínculos institucionais indicam uma diversidade institucional de origem dos pesquisadores que publicaram sobre megaeventos, mas há um destaque: a Turismo e Sociedade, publicada pela Universidade Federal do Paraná (UFPR), publicou os quatro artigos de autores de instituições sediadas no estado do Paraná, concentração local não recomendada pelos critérios de qualificação de periódicos científicos, mas aceitável por se tratar de um número especial.

A distribuição geográfica das instituições de ensino a que os autores estão vinculados indicam concentração nos estados da região Sul, com quatro artigos de autores provenientes do Paraná e um do Rio Grande do Sul. Em seguida, destacamse os estados da região Sudeste, com dois artigos de autores provenientes de instituição de ensino superior (IES) de São Paulo e dois do Rio de Janeiro. Dois artigos são de autores de instituições sediadas em capitais de estados do Nordeste. Não há artigo publicado por pesquisadores de instituições da região Norte. Só há um artigo com autores com vínculo a IES estrangeiras e que também tem um autor vinculada à uma IES da região Centro-Oeste.

Quando se analisam os cursos da última formação ou o vínculo dos pesquisadores, observa-se que, dos 24 autores, nove têm relação direta com turismo e um com hospitalidade. Dos demais, cinco são da área de geografia, 
dois de arquitetura e urbanismo, dois de engenharia da produção, um de marketing, um de história, um de relações internacionais, um de administração e um de economia. Portanto, a maioria dos autores (21\%) são pesquisadores da área de turismo e o caráter interdisciplinar da temática megaeventos e turismo foi evidenciada com a variedade de área dos pesquisadores.

Quadro 4 - Título, palavras-chave e principais resultados extraídos dos artigos

\begin{tabular}{|c|c|c|}
\hline Título & Palavras-chave & Principais resultados extraídos do artigo \\
\hline $\begin{array}{l}\text { 1. Megaeventos: uma } \\
\text { estratégia de atração } \\
\text { turística? }\end{array}$ & \begin{tabular}{|c} 
Megaeventos, \\
Estratégias, \\
Atratividade \\
turística, \\
$\begin{array}{c}\text { Copa do Mundo de } \\
\text { Futebol }\end{array}$ \\
\end{tabular} & $\begin{array}{l}\text { Megaeventos podem contribuir com a promoção da } \\
\text { imagem do país-sede. } \\
\text { Megaeventos esportivos como uma estratégia viável no } \\
\text { estímulo à atratividade turística; ao desenvolvimento } \\
\text { sociocultural; oportunidade de modernização. }\end{array}$ \\
\hline $\begin{array}{l}\text { 2. A gastronomia brasileira } \\
\text { na Copa do Mundo de } \\
\text { Futebol da Fifa 2014: uma } \\
\text { breve análise }\end{array}$ & $\begin{array}{c}\text { Gastronomia, } \\
\text { Megaeventos, Copa } \\
\text { do Mundo 2014, } \\
\text { Brasil }\end{array}$ & $\begin{array}{c}\text { Avaliação parcial das ações poderiam ser desenvolvidas } \\
\text { de forma mais adequada, constatando-se esforços } \\
\text { mínimos para divulgação do patrimônio gastronômico } \\
\text { brasileiro. } \\
\text { Com a inexistência de relatórios parciais e a finalização } \\
\text { do artigo concomitantemente ao andamento das } \\
\text { atividades, recomendou-se avaliação posterior ao } \\
\text { término do evento, no que tange a fluxos turísticos de } \\
\text { médio e longo prazos. }\end{array}$ \\
\hline $\begin{array}{l}\text { 3. Megaeventos } \\
\text { esportivos: reflexões sobre } \\
\text { sustentabilidade e suas } \\
\text { relações com o turismo }\end{array}$ & $\begin{array}{l}\text { Megaeventos, } \\
\text { sustentabilidade, } \\
\text { turismo, } \\
\text { legados }\end{array}$ & $\begin{array}{l}\text { Em eventos anteriores, as ações foram pontuais } \\
\text { e isoladas, não produzindo legado para cidade e } \\
\text { população local. } \\
\text { Considerar de forma integrada as variáveis ambientais } \\
\text { e socioeconômicas no planejamento de infraestrutura } \\
\text { para salvaguarda da sustentabilidade. }\end{array}$ \\
\hline $\begin{array}{l}\text { 4. Copa do Mundo no Brasil: } \\
\text { entre expectativas elevadas } \\
\text { e benefícios imprecisos }\end{array}$ & $\begin{array}{l}\text { Copa do Mundo, } \\
\text { megaevento, } \\
\text { transformações } \\
\text { urbanas, } \\
\text { Curitiba }\end{array}$ & $\begin{array}{l}\text { Disparidade na distribuição de investimentos entre } \\
\text { regiões brasileiras. } \\
\text { Em Curitiba, cidade foco do estudo, as grandes } \\
\text { transformações deram-se na ligação do aeroporto } \\
\text { ao estádio, não viabilizando solução para o problema } \\
\text { urbano da cidade e sim das necessidades impostas } \\
\text { pelo megaevento, resultando acentuação nas } \\
\text { desigualdades de políticas públicas e sociais. }\end{array}$ \\
\hline $\begin{array}{l}\text { 5. Percepção do } \\
\text { residente em relação a } \\
\text { turismo de megaevento: } \\
\text { análise bibliométrica de } \\
\text { periódicos internacionais } \\
\text { e latino-americanos }\end{array}$ & $\begin{array}{l}\text { Turismo, } \\
\text { megaeventos, } \\
\text { residentes, américa } \\
\text { latina, } \\
\text { bibliometria }\end{array}$ & $\begin{array}{l}\text { A partir do recorte, evidenciou-se presença nas } \\
\text { discussões acadêmicas, porém as publicações } \\
\text { provenientes e voltadas ao continente latino estão } \\
\text { à margem do marco teórico. Recomenda-se maior } \\
\text { contingente de publicações sobre a temática e uso } \\
\text { de técnicas e teorias considerando o contexto local. } \\
\text { Necessidade de outras pesquisas, inclusive estudos } \\
\text { bibliométricos na mesma vertente com outros recortes. }\end{array}$ \\
\hline $\begin{array}{l}\text { 6. Pesquisa de identificação } \\
\text { do perfil e satisfação dos } \\
\text { turistas e visitantes de } \\
\text { Brasilia durante a Copa do } \\
\text { Mundo } 2014\end{array}$ & $\begin{array}{l}\text { Turismo, pesquisa } \\
\text { de perfil de } \\
\text { visitantes, } \\
\text { Megaeventos } \\
\text { esportivos, } \\
\text { demanda turística }\end{array}$ & $\begin{array}{l}\text { Perfil visitante no estádio: } 34 \% \text { de São Paulo (nacional); } \\
29 \% \text { Colômbia (internacional). Perfil aeroporto: } \\
\text { motivação da viagem, } 40,9 \% \text { negócios ou trabalho; } \\
53 \% \text { pernoitam } 1 \text { a } 3 \text { dias em Brasília; } 57 \% \text { hospedados } \\
\text { em hotéis; } 64,9 \% \text { viajam com familiares ou amigos; } \\
35 \% \text { pela primeira vez no destino. Avaliações de } \\
\text { satisfação entre muito bom e bom sobre o aeroporto. } \\
\text { Recomendações de procedimentos a serem } \\
\text { considerados nesse tipo de pesquisa. }\end{array}$ \\
\hline
\end{tabular}




\begin{tabular}{|c|c|c|}
\hline Título & Palavras-chave & Principais resultados extraídos do artigo \\
\hline $\begin{array}{l}\text { 7. Cidade mercadoria } \\
\text { cidade-vitrine, } \\
\text { cidade turística: a } \\
\text { espetacularização } \\
\text { do urbano nos } \\
\text { megaeventos esportivos }\end{array}$ & $\begin{array}{l}\text { Megaeventos } \\
\text { esportivos, cidade } \\
\text { espetáculo, } \\
\text { políticas urbanas }\end{array}$ & $\begin{array}{l}\text { A cidade espetáculo não atende a todos, ao mesmo } \\
\text { tempo que o "sucesso" na promoção do turismo } \\
\text { acarreta um custo social, cultural e ambiental. } \\
\text { Articulação entre "turistificação" e interesses do } \\
\text { empreendedorismo urbano; mercantilização de } \\
\text { pedaços em vez do espaço. }\end{array}$ \\
\hline $\begin{array}{l}\text { 8. Um modelo conceitual } \\
\text { de megaeventos musicais }\end{array}$ & $\begin{array}{l}\text { Gestão de } \\
\text { serviços, eventos, } \\
\text { entretenimento, } \\
\text { música }\end{array}$ & $\begin{array}{c}\text { Identificação das etapas para o planejamento } \\
\text { estratégico em megaevento. } \\
\text { Elaboração de um modelo conceitual. }\end{array}$ \\
\hline $\begin{array}{l}\text { 9. Megaeventos } \\
\text { esportivos e relações } \\
\text { internacionais como } \\
\text { estratégia de atração } \\
\text { turística }\end{array}$ & $\begin{array}{l}\text { Copa do Mundo, } \\
\text { Olimpíadas, } \\
\text { turismo, } \\
\text { relações } \\
\text { internacionais }\end{array}$ & $\begin{array}{l}\text { Por meio de medidas e ajuda do poder público- } \\
\text { privado, buscam explorar, com máxima eficiência, a } \\
\text { realização dos megaeventos esportivos consolidando o } \\
\text { Brasil como um país bonito, alegre, próspero, seguro e } \\
\text { líder para o mundo. } \\
\text { Ressalta também que a aferição dos resultados ainda é } \\
\text { muito recente, pois espera-se um primeiro balanço pós } \\
\text { Copa2014 para reajustes nas Olimpíadas. }\end{array}$ \\
\hline $\begin{array}{l}\text { 10. A hospitalidade } \\
\text { urbana de Fortaleza-CE } \\
\text { frente ao megaevento } \\
\text { Copa do Mundo } 2014\end{array}$ & $\begin{array}{l}\text { Hospitalidade urbana, } \\
\text { sinalização turística, } \\
\text { megaevento, Copa } \\
\text { do Mundo }\end{array}$ & $\begin{array}{c}\text { Evidenciou-se que a hospitalidade urbana deve ser voltada } \\
\text { inicialmente para o bem-estar dos moradores, mesmo que } \\
\text { eles não apreciem, conheçam ou percebam a cidade e seus } \\
\text { recursos. } \\
\text { Insatisfação relevante na infraestrutura física da cidade para } \\
\text { receber os turistas. } \\
\text { Atores sociais esperançosos com as mudanças positivas } \\
\text { causadas pelo megaevento. }\end{array}$ \\
\hline $\begin{array}{l}\text { 11. Public participation } \\
\text { in environmental impact } \\
\text { assessment (EIA) and } \\
\text { major sports events: a } \\
\text { comparative analysis of } \\
\text { the London } 2012 \text { Olympic } \\
\text { Games and the Rio } 2007 \\
\text { Pan American Games }\end{array}$ & $\begin{array}{l}\text { Avaliação de } \\
\text { impacto ambiental, } \\
\text { participação } \\
\text { pública, } \\
\text { megaeventos } \\
\text { esportivos, } \\
\text { Jogos Olímpicos, } \\
\text { Jogos Pan } \\
\text { Americanos }\end{array}$ & $\begin{array}{l}\text { Resultados demonstraram que há evidências da } \\
\text { participação pública no processo de Avaliação de } \\
\text { Impacto Ambiental (AIA), apresentam a tomada de } \\
\text { decisão e o processo de planejamento para Londres } \\
2012 \text { e Vila Pan Americana dos Jogos do Rio } 2007 \text {. } \\
\text { Recomendação específica sobre a participação do } \\
\text { público é proposto para o contexto brasileiro, a fim de } \\
\text { reforçar o seu quadro regulamentar para licenciamento } \\
\text { ambiental. } \\
\text { Encoraja-se a realização de pesquisas nessa } \\
\text { temática envolvendo as participações populares no } \\
\text { planejamento e legado dos megaeventos. }\end{array}$ \\
\hline $\begin{array}{l}\text { 12. As mudanças na } \\
\text { imagem das cidades de } \\
\text { Curitiba e Florianópolis: um } \\
\text { estudo sobre os reflexos } \\
\text { da divulgação das cidades } \\
\text { sedes para a Copa do } \\
\text { Mundo da Fifa } 2014\end{array}$ & $\begin{array}{c}\begin{array}{c}\text { Megaeventos, marca } \\
\text { de lugar, imagem de } \\
\text { destino, }\end{array} \\
\text { Curitiba, Florianópolis }\end{array}$ & $\begin{array}{l}\text { Os resultados indicam que, apesar de haver uma diferença } \\
\text { menor no número de reportagens encontradas nos } \\
\text { jornais The New York Times e El País, houve um aumento } \\
\text { na avaliação positiva destas, permitindo acreditar que a } \\
\text { divulgação trouxe reflexos positivos para as cidades. } \\
\text { Curitiba - análise de } 91 \text { artigos no The New York Times } \\
\text { (45) e El País (46), em que os temas são: } 30 \% \text { infraestrutura; } \\
\text { 15\% cultura; } 12 \% \text { economia. Maior retorno na projeção da } \\
\text { imagem ao investir em infraestrutura e sustentabilidade. } \\
\text { Florianópolis - análise de } 32 \text { artigos no The New York Times } \\
\text { (14) e El País (18), sendo: } 29 \% \text { referentes à cultura; } 13 \% \text { ao } \\
\text { turismo. A imagem está fortemente apoiada em turismo. }\end{array}$ \\
\hline
\end{tabular}

Fonte: Autores, 2016.

O Quadro 4 apresenta uma análise referente às palavras-chave e aos principais resultados obtidos pelos estudos, extraídos das discussões dos resultados e/ ou da conclusão do artigo, que foram lidos integralmente na busca de melhor 
ISSN: 1983-7151

compreensão acerca do que foi discutido no artigo. Optou-se pela análise desses itens dos artigos por serem os resumos limitados por um número máximo de palavras ou caracteres em cada periódico. Com este trabalho acurado de análise, considera-se que os dados do presente estudo permitem avaliar a interação que cada pesquisa faz entre megaeventos e turismo.

Analisando, especificamente, as palavras-chaves², observa-se que dois artigos não têm "megaeventos' entre as palavras-chave, "megaeventos" aparece em sete artigos e "megaeventos esportivos" em três, sendo que "Copa do Mundo de Futebol" aparece como palavra-chave de cinco artigos, corroborando com a ideia de que a realização de megaeventos esportivos no Brasil deveria gerar produções científicas.

Por outro lado, "turismo" e o adjetivo "turística" figuram entre as palavras-chave de apenas seis artigos. Dos outros seis que não referenciam a atividade turística ou o turismo nas palavras-chave, foi necessário aprofundar a análise dos conteúdos dos artigos para confirmar se a relação com o turismo estava presente.

O resultado foi que o artigo 2 trata de gastronomia como patrimônio cultural e os resultados indicam a necessidade de pesquisas após a Copa do Mundo 2014 junto à demanda turística, de modo que há relação com turismo.

Considerando os resultados do artigo 4, apreende-se que o trabalho discute a questão da desigualdade social e as transformações urbanas geradas com obras realizadas para a Copa do Mundo, considerando o turismo somente no levantamento de informações no que se refere a transformações urbanas, citando a infraestrutura turística de placas informativas.

O artigo 7 tem relação direta com turismo, pois avalia o custo elevado do megaevento como estratégia de promoção turística e as consequências da "turistificação" dos lugares.

O artigo 8 de fato não tem qualquer relação com turismo: trata de processos para a realização de um megaevento de música como uma atividade de entretenimento.

2 Para a análise das palavras-chave, foram consideradas idênticas as palavras no singular e no plural. Também foram considerados sinônimos: Copa do Mundo de Futebol, Copa de Futebol, Copa do Mundo e Copa do Brasil. Tais diferenças são consequências da falta de um thesaurus consolidado da área, que dificulta muito os estudos bibliométricos. 
A avaliação de impacto ambiental de megaeventos esportivos é o foco do artigo 11, que também enaltece a importância da participação popular no processo de planejamento e de avaliar consequências, entretanto seu conteúdo não menciona turismo.

Por fim, o artigo 12 estuda a divulgação das cidades de Curitiba e Florianópolis em função da Copa do Mundo do Brasil sob o olhar dos conceitos de marca de lugar e imagem dos destinos e conclui que a imagem dessas cidades está fortemente apoiada em turismo.

Portanto, dos doze artigos avaliados, três tratam de megaeventos, mas, nas palavras-chave e nos resultados extraídos de seus conteúdos, não é evidenciada a relação dos trabalhos com o estudo do turismo, apesar de terem sido publicados em periódicos especializados da área.

Por outro lado, é possível destacar que os principais temas abordados no referencial teórico sobre megaeventos (como legado, impactos, participação da comunidade, marketing de lugar, infraestrutura urbana e facilidades construídas para o evento) figuram nas discussões teóricas dos artigos investigados.

\section{CONSIDERAÇÕES FINAIS}

O objetivo deste estudo foi analisar o conhecimento científico dos periódicos de turismo brasileiros quanto à produção acerca de megaeventos nos últimos cinco anos, por meio de um estudo bibliométrico.

Dentre os 1.760 artigos publicados de janeiro de 2010 a dezembro de 2015, em 13 periódicos de turismo analisados, apenas 12 foram sobre megaeventos, representando cerca de 0,02\% dos trabalhos no período de cinco anos, mostrando restrita produção científica dos pesquisadores no estudo e na publicação nos periódicos nacionais sobre o tema, em contraposição a uma fase auge do Brasil como sede de jogos mundiais. Dos artigos identificados, nove eram referentes a megaeventos esportivos, um sobre megaeventos musicais, outro sobre estratégia turística e um sobre turismo de megaeventos. 
A partir das definições levantadas no referencial teórico, discutidas por pesquisadores que relacionam megaeventos e turismo, é possível afirmar que, dos 12 artigos encontrados: quatro abordam temáticas que se aproximam das discussões de megaeventos como um elemento do marketing de cidades, estudando a imagem ou a capacidade de atração de turistas de cidadessede; três valorizam a participação da comunidade local nos processos de planejamento e execução de megaeventos, priorizando os moradores quando se pensa em legado; dois exploram diretamente o conceito de legado e sua aplicabilidade; um avalia a satisfação dos visitantes que participaram de um megaevento; um aborda a importância do planejamento urbano para o sucesso de megaeventos; e, por fim, o último traz dados pontuais sobre etapas a serem seguidas no planejamento de um megaevento. Assim, conclui-se que as abordagens de megaeventos nos periódicos brasileiros coincidem com as reflexões das pesquisas internacionais sobre o tema.

Entretanto, o levantamento realizado indica uma marginal importância dada à relação "megaeventos e turismo" pelos pesquisadores brasileiros, o que não se justifica, considerando-se o fato de o país ter sediado, na última década, importantes megaeventos, além dos esportivos. Dos artigos publicados, um foi no ano de 2012, dois em 2013, seis em 2014 e três em 2015, o que mostra um pequeno aumento no número de publicações sobre megaeventos nos últimos dois anos.

Entretanto, a variedade de área de pesquisa dos autores e de instituições de ensino de origem indica o quão importante são as diferentes visões do setor e sua relação com o turismo, o que contribui com críticas e impulsiona no questionamento dos megaeventos, mesmo que nem todos trabalhos tenham relação direta com o estudo do turismo. Os dados revelam que há uma diversificação da produção científica sobre megaeventos beneficiando setores direta e indiretamente relacionados, além de contribuir com a qualidade da produção intelectual ligada a turismo.

Este estudo entende a necessidade de mais produção acerca de turismo e megaeventos que tenham como fundamentação a importância de um segmento para o outro, bem como infinitas possibilidades de incremento de ações que permitam um benefício mútuo entre essas atividades. 
Vale ressaltar que o trabalho analisa somente artigos que usam megaeventos no título ou nas palavras-chave e revistas nacionais com a palavra turismo no nome ou ligadas aos programas de pós-graduação em turismo, havendo, no entanto, diversos trabalhos publicados em outros veículos (revistas das áreas de educação física, políticas públicas, educação, meio ambiente) que se correlacionam ao conceito multidisciplinar de turismo. São cada vez mais necessários estudos críticos com análises aprofundadas na teoria e na realidade. Este artigo espera aguçar futuras pesquisas que colaborem com o presente estudo.

\section{REFERÊNCIAS}

Alberini, B. (2014). Megaeventos: uma estratégia de atração turística? Turismo e Sociedade, Curitiba, v. 7, n. 1, p. 64-76.

Araújo, C.A. (2006). Bibliometria: evolução histórica e questões atuais. Em Questão. Porto Alegre, v. 12, n. 1, p. 11-32, jan./jun.

Araújo, R.F.; Alvarenga, L. (2011). A bibliometria na pesquisa científica da pós-graduação brasileira de 1987 a 2007. Enc. Bibli: R. Eletr. Bibliotecon. Ci. Inf., Florianópolis, v. 16, n. 31, p. 51-70, 2011.

Arquiteturismo. (s/d). Expediente. Disponível em: http://www.vitruvius.com.br /revistas/ expedient/arquiteturismo. Acesso em: 25/10/2015.

BAHL, M. Editorial. Turismo e Sociedade. v.7 n. 1, p. 7-15, 2014.

Barbosa, F.S. e Scarvada, A.J. (2015). Um modelo conceitual de megaeventos musicais. Cultur - Revista de Cultura e Turismo, Ilhéus (BA), v. 9, n. 2, p. 135-150, 2015.

Basso, K.G.F.; Andrade, T.C. e Bittencourt, A.P. (2015). Pesquisa de Identificação do perfil e satisfação dos turistas e visitantes de Brasília durante a Copa do Mundo 2014. Turismo em Análise. São Paulo, v. 26, n. 1, p. 68-91.

Brasil. Ministério do Turismo. (2013). Plano Nacional de Turismo 2013-2016. Brasília, DF.

Britto, J.; Fontes, N. (2002). Estratégia para eventos: uma ótica do marketing e do turismo. - São Paulo: Aleph.

Cavalcanti, M.N. e Lima, I.C. (2013). A hospitalidade urbana de Fortaleza-CE frente ao megaevento Copa do Mundo de 2014. Turismo: Estudos e Práticas. Mossoró (RN), v. 2, n. 2, p. 107-132. 
Firkowski, O.L.C.F; Baliski, P. e Ferreira, A.G. (2014). Copa do Mundo no Brasil: entre expectativas elevadas e benefícios imprecisos. Turismo e Sociedade. Curitiba, v. 7, n. 1, p. 41-63.

Freitag, B.B.; Tiscoski, G.P. e Moretto Neto, L. (2010). Análise da produção acadêmica em administração sobre turismo. 34 EnANPAD, Rio de Janeiro, p. 1-13.

Funk, D. e Bruun, T. (2007). The role of socio-psychological and culture-education motives in marketing - international sport tourism: a cross-cultural perspective. Tourism Management, 20 (3), 806-819.

Getz, D. (2008) Event tourism: definition, evolution and research. Tourism Management. 29; p. 403-428.

Gimenes-Minasse, M.H.S.G. (2014). A gastronomia brasileira na Copa do Mundo de Futebol da FIFA 2014: uma breve análise. Turismo e Sociedade. Curitiba, v. 7, n. 1, p. 77-98.

Hall, M. (2011). Publish and perish? Bibliometric analysis, journal ranking and the assessment of research quality in tourism. Tourism Management. V. 32. p. 16-27.

Hall, C.M. (2006). Urban entrepreneurship, corporate interests and sports mega-events: The thin policies of competitiveness within the hard outcomes of neoliberalism. In: HORNE, J e MANZENREITER, W. (orgs). Sports mega-events: Social scientific analyses of a global phenomenon. Oxford: Blackwell, p. 59-70.

ICCA - International Congress and Convention Association. (2014) The international association meetings market 2014 - ICCA statistic report 2014. Disponível em: <www. iccaworld.com/dcps/doc.cfm?docid=1789>. Acesso em 30 de abril de 2016.

Ishiy, M. (1998). Turismo e megaeventos esportivos. Turismo em Análise. São Paulo, v. 9, n. 2, p. 47-61.

Jago, L.; Dwyer, L.; Lipman, G.; Lill, D. e Vorster, S. (2010). Optimising the potential of mega-events: an overview. International Journal of Event and Festival Management, v. 1 , p. $220-237$.

Jesus, G.M. (2014). Cidade mercadoria, cidade-vitrine, cidade turística: a espetacularização do urbano nos megaeventos esportivos. Caderno Virtual de Turismo. Rio de Janeiro, v. 14, n. especial, p. 52-65.

Kotler, P; Gertner, D.; Rein, I e Haider, D. (2006). Marketing de lugares: como conquistar crescimento ao longo prazo na América Latina e no Caribe. São Paulo: Prentice Hall.

Lohmann, G. e Panosso Netto, A. (2008). Teoria do turismo: conceitos, modelos e sistemas. São Paulo: Aleph. 
Marcellino, N.C. (org.). (2013). Legados de megaeventos esportivos. Campinas, SP: Papirus. (Coleção Fazer/Lazer).

Matias, M. (2008). Os efeitos dos megaeventos esportivos nas cidades. Turismo e Sociedade. Curitiba, v. 1, n. 2, p. 175-198.

Milito, M.C; Marques, S. e Alexandre, M.L. (2013). Percepção do residente em relação a turismo e megaevento: análise bibliométrica de periódicos internacionais e latinoamericanos. Turismo em Análise. São Paulo, v. 24, n. 3, p. 482-502.

Oliveira, A. P. (2002). Turismo e desenvolvimento: planejamento e organização. 4. ed. São Paulo: Atlas.

Owen, J. (2005). Estimating the cost and benefit of hosting Olympic Games: what can Beijing expect from its 2008 Games? The Industrial Geographer. v.3, n.1, p.1-18.

Pace, T.H. e Hardt, L.P.A. (2014). Megaeventos esportivos: reflexões sobre sustentabilidade e suas relações com o turismo. Turismo e Sociedade. Curitiba, v. 7, n. 1, p. 16-40.

Pace, T.H.; Hardt, L.P.A. e Figueiredo, F.C. (2015). Sorting mega-events and tourism: bibliometric relationships in academia. Business and Management Review, v. 4, n.12, May.

Panosso Netto, A. (2010). O que é turismo. São Paulo: Brasiliense. (Coleção primeiros passos).

Pereira, G.S. e Conto, S.M. (2014). Public Participation in environmental impact assessment (EIA) and major sports events: a comparative analysis of the London 2012 Olympic Games and the Rio 2007 Pan American Games. Revista Rosa dos Ventos. Caxias do Sul (RS), v. 6, n. 4, p. 488-507.

QUALIS-CAPES. (s/d). Periódicos classificação 2014 área de Administração, Ciências Contábeis e Turismo. Disponível em: Disponível em: shttps://sucupira.capes.gov.br/ sucupira/public/consultas/coleta/veiculo PublicacaoQualis/listaConsultaGeralPeriodicos. jsf >. Acesso em 02/11/2015.

Reis, A.C. (2008). Megaeventos e turismo: uma breve revisão. In Rodrigues, R.P.; DaCosta, L; Pinto, L.M.; Terra, R. Legados de megaeventos esportivos. Ministério do Esporte. DF, Brasil.

Ribeiro, C.H.V.; Soares, A.J.G. e Dacosta, L.P. (2014). Percepção sobre o legado dos megaeventos esportivos no Brasil: o caso da Copa do Mundo FIFA 2014 e os Jogos Olímpicos 2016. Revista Brasileira de Ciências do Esporte. Florianópolis, v. 36, n. 2, p. 447-466, abril/junho.

Roche, M. Mega events and urban policy. (1994). In: Annals of Tourism Research. 21, 1994, Nova York. Anais... Nova York: Pergamon Press, 1994. 
Rodrigues, R.P.; Dacosta, L., Pinto, L.M. e Terra, R. (2008). Legados de megaeventos esportivos. Ministério do Esporte. DF, Brasil.

Romano, F.S; Vico, R.P.; Silva, A.C.; Uvinha, R.R. (2015). Megaeventos esportivos: Uma reflexão sobre os legados da UEFA Eurocopa. Revista Podium, Sport, Leisure and Tourism Review. v. 4, n. 3, setembro/dezembro.

Ruschmann, D.M. e Solha, K.T. Planejamento turístico. Barueri (SP): Manole, 2006.

Santos, M.P. (2000). Da Expo'98 ao Euro 2004: notas para o estudo do impacto de grandes eventos no turismo regional. Educação e Comunicação. (4). 22-47.

Silva, I.O.F. (2012). Megaeventos esportivos e relações internacionais como estratégia de atração turística. Revista Acadêmica Observatório de Inovação do Turismo. Rio de Janeiro, v. 7, n. 1.

Silva, S.B.M.; Carvalho, S.S e Silva, B.C.M.N. (2009). Globalização, turismo e residências secundárias: o exemplo de Salvador-Bahia e de sua região de influência. Revista Acadêmica Observatório de Inovação do Turismo, Rio de Janeiro, v. 4, n. 3.

Tavares, O. (2007). Instalações temporárias do Pan Rio 2007: possíveis legados. In: Rubio, K. (Org.). Megaeventos esportivos, legado e responsabilidade social. São Paulo: Casa do Psicólogo.

Trotta, S.T.; Strehlau, V.I. e Turolla, F.A. (2015). As mudanças na imagem das cidades de Curitiba e Florianópolis: um estudo sobre os reflexos da divulgação das cidades sedes para a Copa do Mundo da Fifa 2014. Revista Turismo Visão e Ação, Balneário Camboriú (SC), v.17, n.2, ago.

Tyler, D.; Guerrier, Y. e Robertson, M. (orgs.). (2001). Gestão do turismo municipal: teoria e prática de planejamento turístico nos centros urbanos. (tradução Gleice Guerra). São Paulo: Futura.

Veal, A. J. (2011). Metodologia de pesquisa em lazer e turismo. Tradução Gleice Guerra, Mariana Aldrigui. São Paulo: Aleph. 